
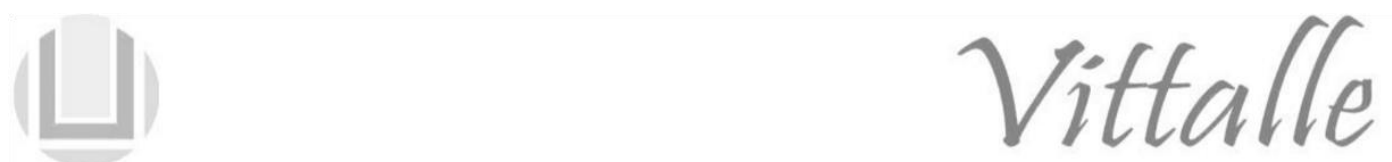

\title{
Suplementos alimentares, imunidade e COVID-19: qual a evidência?
}

\author{
José Henrique Gialongo Gonçales Bomfim ${ }^{\mathrm{a}^{*}}$, Juliana da Silveira Gonçalves ${ }^{\mathrm{b}^{*}}$ \\ ${ }^{a}$ Conselho Federal de Farmácia - CFF, Brasília, DF, Brasil \\ bUniversidade do Vale do Taquari - UNIVATES, Porto Alegre, RS, Brasil
}

Histórico do Artigo
Recebido em:
20/04/2020
Aceito em:
29/05/2020
Palavras-chave:
suplementos
alimentares;
imunidade;
COVID-19

Keywords: dietary supplements; immunity; COVID-19

\begin{abstract}
RESUMO
Em março de 2020, a Organização Mundial da Saúde declarou a COVID-19 como pandemia, e a busca por compostos que pudessem reduzir os agravos da doença ou mesmo estabelecer uma cura efetiva, se espalhou pela comunidade científica. Além de medicamentos já utilizados em outras condições, alguns estudos tem buscado evidenciar a utilização de compostos naturais, vitaminas, aminoácidos, proteínas, minerais e ácidos graxos, que possam promover benefício na resposta imunológica ou desempenharem efeitos antivirais. O presente trabalho teve o objetivo de revisar na literatura, a utilização de suplementos alimentares, em dosagens permitidas pela legislação brasileira e seu papel na melhora da imunidade ou na resposta a infecções virais. Os dados sugerem que o estado nutricional é fator determinante para uma boa resposta imunológica, e isso é alcançado no equilíbrio da disponibilidade de micro e macronutrientes. Conclui-se que, nas doses recomendadas pela legislação vigente, os suplementos alimentares apresentam impacto discreto em relação aos sintomas de agravo da COVID-19, quando analisados de forma isolada.
\end{abstract}

Dietary supplements, immunity and COVID-19: what is the evidence?

\section{ABSTRACT}

In March of 2020, the World Health Organization declared COVID-19 to be a pandemic, and the search for compounds that could reduce the negative effects of the disease or even establish an effective cure, spread throughout the scientific community. In addition to medications already used in other conditions, several studies show the use of natural compounds, vitamins, amino acids, proteins, minerals and fatty acids, which can promote benefits in the immune response or have antiviral effects. This study aimed to review in the literature, the use of dietary supplements, in dosages allowed by Brazilian legislation and their role in improving immunity or in responding to viral infections. The data suggest that nutritional status is a determining factor for a good immune response, and this is achieved by balancing the availability of micro and macronutrients. It is concluded that, in the doses recommended by the current legislation, dietary supplements have a slight impact in relation to the symptoms of COVID-19, when analyzed in isolation.

\section{Introdução}

A Organização Mundial de Saúde declarou, em 11 de março de 2020, a Síndrome Respiratória Aguda Grave - COVID - 19 (SARS - CoV-2), causada pelo coronavírus, como pandemia, sendo esta uma doença infecciosa de alta consequência (1). Este patógeno foi primariamente identificado em janeiro de 2020, após diversos casos de infecções respiratórias serem reportados ao final de 2019, na cidade de Wuhan, província de Hubei, na China. O vírus então foi nomeado 2019-n-CoV pela Organização Mundial de Saúde, sendo posteriormente renomeado como SARS - CoV-2. O SARS - CoV-2 é um subtipo de coronavírus, pertencente a uma família de aproximadamente 30 diferentes vírus com a capacidade de afetar a espécie humana (2). Os principais sintomas apresentados são febre, fadiga e tosse seca, podendo evoluir para dispneia ou, em casos mais graves, Síndrome Respiratória Aguda Grave, linfopenia e achados nos exames de

\footnotetext{
*Autores correspondentes: drhenrique@msn.com (Bomfim J.H.G.G.) e jusg.nutri@gmail.com (Gonçalves J.S.)
} 
imagem do tórax sugestivos de pneumonia. Entretanto, há um grande número de pacientes infectados que não apresentam sintomas. $O$ tempo exato de incubação não foi determinado; as estimativas variam de 1 a 14 dias.

Os fatores de risco para o agravamento dos sintomas ainda não estão totalmente esclarecidos. Além de imunossuprimidos e idosos, condições crônicas como doença pulmonar crônica, doença cardiovascular, diabetes mellitus e hipertensão, parecem aumentar o risco de graves resultados associados à patogenia do COVID-19 $(2,4)$. Embora o papel da obesidade tenha sido inicialmente negligenciado (5), dados de relatórios recentes $(6,7)$, indicam que a obesidade está associada a graves resultados do COVID-19. O risco de um quadro mais grave da doença, assim como o número de óbitos pelo covid-19, aumenta com a idade.

Diante do crescente número de infectados e óbitos ocorridos pela doença no mundo, diversos pesquisadores e instituições iniciaram testes com agentes que poderiam ser utilizados para prevenção da infecção ou cura da doença. Há, então, na comunidade científica, uma busca por qualquer tipo de composto que possa prevenir a infecção causada pelo coronavírus, reduzir o tempo ou o agravamento dos sintomas da doença, ou ainda trazer uma cura efetiva. Estes agentes seriam ferramentas para potencializar a resposta imunológica ou mesmo impedir a replicação viral, reduzindo assim os casos de infecção pela COVID-19 no planeta.

É de conhecimento global que o estado nutricional interfere diretamente na resposta imunológica, sendo que em populações onde, em sua alimentação, são observadas carências nutricionais, há uma maior incidência de desenvolvimento de diversas patologias, e o processo de recuperação da doença tende ser mais longo (8). Neste contexto, o uso de suplementos alimentares como complemento da alimentação pode trazer benefícios em relação à resposta imunológica, reduzindo o poder de infecção de determinados patógenos, ou mesmo acelerando o processo de recuperação do indivíduo (9).

No Brasil, os suplementos alimentares são definidos pela Resolução da Agência Nacional de Vigilância Sanitária - ANVISA no 243/2018 como "produto para ingestão oral, apresentado em formas farmacêuticas, destinado a suplementar a alimentação de indivíduos saudáveis com nutrientes, substâncias bioativas, enzimas ou probióticos, isolados ou combinados", não podendo conter em seus rótulos alegações/finalidade medicamentosa ou terapêutica, seja ela preventiva, paliativa ou curativa. Tais componentes devem fazer parte de uma estratégia que visa atender às necessidades de saúde do indivíduo, e sua utilização deve servir de recurso complementar, no contexto de um estilo de vida saudável (dieta, atividade física, saúde mental, bem-estar social) (10).

De acordo com esta Resolução, se enquadram nesta definição suplementos de vitaminas e minerais, substâncias bioativas e probióticos, novos alimentos, alimentos com alegação de propriedade funcional, suplementos para atletas e complementos alimentares para gestantes e nutrizes. Os valores mínimos e máximos de utilização dos compostos, na recomendação diária de consumo e por grupo populacional indicado pelo fabricante, bem como as alegações de uso dos compostos, cuja segurança fora comprovada, estão descritos na Instrução Normativa $n^{\circ} 28$ de 2018, também publicada pela ANVISA (11).

É importante salientar que, em outros países, os termos "suplemento" ou "nutracêutico", são utilizados para compostos que não se aplicam à legislação brasileira vigente, sendo estes, muitas vezes, classificados aqui como medicamentos isentos de prescrição (MIPs) ou medicamentos fitoterápicos. Ainda não há, na literatura científica, um consenso ou recomendação do uso de nutrientes ou compostos bioativos, em doses permitidas em suplementos alimentares no Brasil, com desfecho benéfico que represente redução da carga viral em infecções, aumento da resposta imunológica ou mesmo como prevenção de afecções virais agudas ou crônicas. 
A legislação vigente para requisitos sanitários para suplementos alimentares ( $\mathrm{RDC} \mathrm{n}^{\circ}$ 243/2018 e IN $n^{\circ}$ 28/2018), permite a alegação de uso em rótulos dos produtos classificados como "auxiliares no funcionamento do sistema imune". Dentre todos os compostos destacados na legislação, os que possuem tal alegação de uso são o ácido fólico, vitamina A, vitamina B12, vitamina B6, vitamina C, vitamina D, cobre, ferro, selênio e zinco, com seus limites máximos de recomendação diária como suplementos alimentares, mas não atribui propriedade terapêutica ou medicamentosa a estes compostos (11).

Portanto, o presente artigo teve como objetivo realizar uma revisão descritiva sobre os possíveis efeitos do uso de suplementos alimentares na resposta imunológica, quando utilizados nas dosagens determinadas pela legislação vigente, e sua relação com patógenos virais na prevenção ou tratamento da infecção respiratória causada pelo coronavírus.

\section{Nutrição e Resposta Imunológica}

A infecção por SARS-CoV-2 tende a ativar respostas adaptativas durante o período de infecção, onde fatores ligados ao hospedeiro desencadeiam uma resposta imunológica contra o vírus. No entanto, este processo pode dar início a uma imunopatogênese associada à resposta imunológica fora de controle, resultando em danos nos tecidos pulmonares, com comprometimento e redução da capacidade pulmonar. Fatores quimiotáticos são essenciais às respostas imunológicas contra as infecções virais, dado seu efeito regulador nas dilatações e posições dos leucócitos nos pulmões do hospedeiro. Portanto, alterações espectrais nos fatores quimiotáticos podem levar a respostas imunológicas severamente desajustadas (12).

Nos casos de maior gravidade, ocorre resposta inflamatória descontrolada e comprometimento adaptativo da resposta imunológica, que pode levar a danos teciduais prejudiciais, localmente e sistemicamente. Esta resposta inflamatória ao patógeno é caracterizada por uma "tempestade de citocinas", principalmente interleucinas (IL-1B, IL-2, IL-6) e fator de necrose tumoral (TNF). Os altos níveis de citocinas próinflamatórios podem também levar a choque e dano tecidual no coração, fígado e rim, bem como insuficiência respiratória ou falência de múltiplos órgãos. Eles também mediam extensa patologia pulmonar, levando a infiltração maciça de neutrófilos e macrófagos, dano alveolar difuso com a formação de membranas hialinas e uma difusa espessamento da parede alveolar (13).

Apesar de ainda não estar totalmente esclarecido o papel da resposta imunológica inata no processo de evolução da infecção pelo SARS - CoV-2, sabe-se que a manutenção deste sistema é fundamental para que o indivíduo possa produzir respostas a agentes infecciosos, buscando a recuperação e impedindo o agravamento das doenças.

Os eventos ligados ao desequilíbrio no estado nutricional, má nutrição e implicação destes no sistema imunológico, estão bem caracterizados na literatura científica, e estes componentes possuem ligação íntima na integridade da resposta imunológica devido ao déficit energético e indisponibilidade de micronutrientes essenciais, que podem ser rapidamente afetados por alterações no estado nutricional (14).

Entretanto, o alcance do equilíbrio nutricional e a consequente homeostasia metabólica do organismo ainda são um grande desafio, diante de questões multifatoriais extrínsecas, como problemas sócio econômicos, questões culturais, saneamento básico, hábitos e estilos de vida, doenças crônicas e outros fatores que podem influenciar no acesso uma alimentação adequada, e isto pode acarretar em consequências metabólicas onde o equilíbrio tende a não ser atingido. 
As consequências deste desequilíbrio podem ter extrema magnitude na resposta imunológica, uma vez que órgãos e tecidos produtores de células do sistema imunológico, imunoglobulinas, sistema complemento, microbioma intestinal, defensinas e outras substâncias que participam da resposta imunológica, são diretamente afetados, levando o sistema à imunossupressão (15).

Cabe ressaltar que o estado de desnutrição pode estar diretamente ligado a dois extremos da oferta de alimentos. Existe a subnutrição associada à baixa oferta de alimentos, diretamente ligada à pobreza extrema, onde os indivíduos não tem acesso mínimo para suprir suas necessidades calóricas diárias, em termos quantitativos e qualitativos. Por outro lado, há uma crescente epidemia de indivíduos com sobrepeso, caracterizado pelo acúmulo excessivo de gordura no tecido adiposo, estes com acesso ao alimento, mas onde a qualidade nutricional da dieta leva ao desenvolvimento de quadros crônicos como obesidade e síndrome metabólica, com alimentos altamente energéticos, hipercalóricos e com baixo valor nutricional. Ambos os cenários se traduzem em quadros de desnutrição, o que afetaria diretamente a resposta imunológica e, consequentemente, podendo agravar os quadros de doenças infecciosas. Além disso, o processo inflamatório gerado pela obesidade pode ser um agravante das condições inflamatórias já citadas anteriormente, nos casos de avanço da patologia por coronavírus. Kalligeros et al. (16), avaliaram a possível associação entre obesidade e agravamento de sintomas em pacientes hospitalizados com COVID-19. Os resultados do estudo indicaram que pacientes com grau severo de obesidade (Grau III, IMC $>35 \mathrm{~kg} / \mathrm{m}^{2}$ ), tiveram admissão na unidade de terapia intensiva, devido à gravidade dos sintomas apresentados, o que sugere uma associação dos eventos associados à obesidade em relação ao agravamento dos sintomas da COVID-19.

Simonnet et al. (17), também demonstraram alta prevalência de pacientes com diferentes graus de obesidade, admitidos em unidades de terapia intensiva, com Síndrome Respiratória, em decorrência da COVID-19, indicando que a severidade dos eventos aumenta em pacientes obesos, sendo esta doença, um fator de risco para os pacientes da COVID-19. Uma das explicações prováveis sobre o aumento na severidade dos sintomas relacionados à COVID-19, reside no fato de que, na obesidade, ocorre secreção anormal de adipocinas e citocinas como TNF-alfa e interferon, característica inflamatória da obesidade abdominal, que pode prejudicar a resposta imunológica (18) e têm efeitos no parênquima pulmonar e nos brônquios. Estes dados demonstram que o controle da obesidade, relacionado à nutrição, seria de fundamental importância para a possível diminuição dos agravos relacionados ao COVID-19.

Berthon e Wood (19), descrevem o papel da nutrição na saúde respiratória e os fatores de risco de determinadas dietas para o desenvolvimento de doenças no sistema. Os autores relatam os benefícios de dietas, como a mediterrânea, ricas em alimentos com compostos antioxidantes, vitaminas A, D, E, C, flavonoides, ácidos graxos poli-insaturados, ômega 3 , minerais e o efeito positivo destes nutrientes em pacientes com doença pulmonar obstrutiva crônica e asma, bem como os efeitos negativos de dietas ocidentais, ricas em grãos refinados, carnes curadas, doces, pobres em fibras e nutrientes essenciais, além dos eventos inflamatórios da obesidade e sua ligação a estas patologias.

O estado nutricional e a relação com as funções imunológicas também foram explorados por Sayarlioglu et al. (20), com pacientes em hemodiálise. Estes pacientes apresentam quadros de subnutrição, ocasionada pela carência de nutrientes essenciais, o que levaria ao desenvolvimento de quadros respiratórios relacionados a mau funcionamento do sistema imunológico e consequente diminuição na produção de células do sistema imune e componentes que atuam no sistema de defesa do organismo. É indiscutível que a deficiência ou inadequação nutricional pode prejudicar as funções imunológicas. 


\section{Suplementos alimentares}

É importante reforçar que suplementos alimentares são nutrientes em diferentes formas farmacêuticas que fazem parte de uma estratégia nutricional para indivíduos saudáveis, quando estes não alcançam suas necessidades nutricionais suficientes de micro e macronutrientes através da alimentação. Os mesmos, pela legislação vigente no país, só devem ser utilizados ou prescritos por profissionais legalmente habilitados, dentro dos limites determinados pela IN $n^{\circ} 28 / 2018$, seguindo as recomendações de ingestão diária recomendada ( $\mathrm{RDC} \mathrm{n}^{\circ}$ 269/2005).

Entre os nutrientes com eficácia na resposta imunológica, as vitaminas, minerais, ácidos graxos e compostos bioativos, são elencados como os principais e, quando de sua deficiência, são observados desfechos negativos em relação ao curso de doenças infecciosas. Evidências crescentes sugerem que, para certos nutrientes, o aumento da ingestão acima dos níveis atualmente recomendados pode ajudar a otimizar as funções imunológicas, incluindo a melhora da função de defesa e, portanto, a resistência à infecção, mantendo a tolerância.

Muitos desses componentes alimentares nutritivos e não nutritivos estão relacionados em suas funções para manter ou melhorar a função imunológica, incluindo inibição de mediadores pró-inflamatórios, promoção de funções anti-inflamatórias, modulação da imunidade mediada por células, alteração das funções celulares apresentadoras de antígenos e comunicação entre os sistemas imunológicos inato e adaptativo.

Entre estes nutrientes podemos destacar os ácidos graxos poli-insaturados n-3 (PUFA), micronutrientes (zinco, vitaminas D e E) e alimentos funcionais, incluindo probióticos e componentes do chá verde (epigalocatequina-3-galato) por seus efeitos imunológicos.

Aslam et al. (21), destacam o papel das vitaminas A, C, D, E, B6, B12 e folato como promotores da melhora na resposta imunológica, e que o adequado aporte destes nutrientes aumenta a atividade de linfócitos $\mathrm{T}$, anticorpos, além de regular a produção de citocinas, defensinas e demais compostos que participam da resposta imunológica. Os autores ainda destacam que a suplementação destas vitaminas pode ser um grande aliado no suporte às defesas naturais do organismo.

Zhang e Liu (22), descrevem como as intervenções nutricionais e alguns compostos bioativos podem ser potenciais intervenções ao COVID-19. Os autores relatam que não é comum ser avaliado o estado nutricional dos pacientes contaminados e sugerem que isso seja realizado anteriormente ao tratamento dos infectados. Como a China foi o país onde a infecção pelo COVID-19 teve seu início, há uma corrida para serem testadas todas as formas de tratamento já conhecidas e que possuem eficácia em infecções virais respiratórias com semelhança ao COVID-19. Os autores ainda destacam a possível utilização de micronutrientes, como vitaminas e minerais, como coadjuvantes na recuperação dos pacientes e também compostos bioativos, principalmente alguns da medicina chinesa tradicional, como clicirrizina (raiz de alcaçuz), baicalina (flavonoide da Radix Scutellaria) e ginseng (Panax ginseng), estes com alegação de ação positiva potencial em infecções virais, melhorando as defesas naturais dos infectados ou mesmo inibindo a replicação viral por diversos mecanismos.

Além destes compostos, os autores sugerem a atividade anti-coronavírus de alguns flavonoides (Herbacetina, rhoifolin e pectolinarina) devido à inibição de protease do tipo 3C (3 chymotrypsin-like - 3CLpro) e outros flavonoides (herbacetina, isobavachalcona, quercetina 3- $\beta$-d-glucosídeo e helicrysetina), que também seriam capazes de bloquear a atividade enzimática de MERS - CoV / 3CLpro, bem como bi flavonoides de Torreya nucifera, que teria efeito inibidor da SARS - CoV / 3CL. 
Um estudo recente publicado por Khaerunnisa et al. (23), avalia o efeito inibitório da principal protease do COVI-19 (COVID-19 M $^{\text {pro }}$ ) através de ensaios de docking molecular. Diversos compostos bioativos foram testados e comparados a agentes antiretrovirais clássicos. Os compostos kaempferol, quercetina, luteolin, desmetoxicurcumina, naringenina, apigenina, oleuropeína, curcumina, catequina e galato-epicatequina, encontrados em algumas plantas medicinais e alimentos, foram destacados como tendo maior potencial de efeitos positivos em relação ao COVID-19 $\mathrm{M}^{\text {pro }}$. Entretanto, este foi apenas um ensaio computacional que requer melhor investigação dos compostos em novos ensaios in vitro e in vivo.

O mesmo tipo de ensaio de docking foi explorado por Zhang et al. (24), utilizando compostos da medicina tradicional chinesa com potencial atividade antiviral. Os autores descrevem 13 compostos com essa possível atividade, encontrados em 125 ervas, onde 26 destas são classificadas para utilização em infecções no trato respiratório. Os resultados sugerem que estas ervas podem ser investigadas em mais ensaios in vitro e in vivo, devido aos possíveis efeitos antivirais apresentados pelos compostos.

\section{Vitaminas e minerais}

É consenso que vitaminas e minerais exercem papel fundamental na manutenção do equilíbrio do metabolismo, bem como das funções celulares ligadas à defesa e recuperação do organismo. Existe controvérsia em relação às dosagens diárias de cada nutriente, principalmente no que tange ao funcionamento adequado do sistema imune, uma vez que não se deve somente levar em consideração este fator para uma melhor resposta do indivíduo ao processo infeccioso.

Alguns compostos vêm sido descritos como potenciais ferramentas no controle, prevenção e até mesmo recuperação de afecções do trato respiratório. Dentre eles, destacamos as vitaminas A, D, C, complexo B e os minerais, zinco e selênio.

A vitamina A auxilia no sistema imune, por modular a resposta de células fagocitárias, favorecendo a fagocitose. O papel da vitamina A na resposta imunológica foi explorado por Huang et al. (25), destacando seu papel na formação dos tecidos epiteliais e mucosas, proliferação e regulação da apoptose de timócitos; regulação da diferenciação, maturação e função de células do sistema imune inato (macrófagos, natural T killer, células linfóides, linfócitos T, células B), além da ação direta em determinados distúrbios infecciosos, como tuberculose, HIV, malária e pneumonia.

Em revisão Cochrane, Chen et al. (26), avaliaram os efeitos da vitamina A em prevenir infecções respiratórias agudas em crianças. Nesta revisão com dez estudos e mais de 30.000 participantes, os autores concluíram que vitamina A não deve ser administrada a todas as crianças para prevenir infecções agudas do trato respiratório e que a mesma tem apenas um efeito limitado na prevenção destas infecções. Os efeitos positivos parecem limitados às populações com subnutrição aguda e crônica.

A vitamina $\mathrm{C}$, também conhecida como ácido ascórbico, é uma vitamina hidrossolúvel fundamental para o nosso organismo, com um alto poder antioxidante o que impacta positivamente no sistema imune. Apesar desta vitamina ser indicada há décadas para prevenção de gripes e resfriados (27), não existe um consenso de quais seriam as dosagens efetivas para quaisquer outras condições do trato respiratório, seja como prevenção ou tratamento. Hemilä e Louhiala (28), revisaram o papel da vitamina C na prevenção da pneumonia. Os autores concluíram que, mesmo com este composto já sendo utilizado para tal finalidade, as evidências para esta situação não se sustentam e algum efeito pode ser positivo para aqueles cuja ingestão diária esteja dentro dos limites recomendadas (até $2 \mathrm{~g}$ ao dia). 
Hemilä e Chalker (29), também em revisão Cochrane, avaliaram os dados de vinte e nove estudos, com mais de 11.000 participantes, sobre os efeitos preventivos da vitamina $\mathrm{C}$ no resfriado comum, uma de suas principais alegações de uso. Os autores concluíram que a vitamina $\mathrm{C}$ falhou em reduzir a incidência de resfriado comum nos participantes. Entretanto, houve um pequeno impacto positivo na redução do tempo de duração da condição e que as dosagens e uso devem ser testadas individualmente.

Dentre todas as vitaminas, talvez a que esteja em maior evidência, diante de dezenas de publicações que relatam potenciais efeitos na prevenção ao COVID-19, seja a vitamina D. É de notório saber que a vitamina $\mathrm{D}$ possui efeitos positivos em relação à resposta imunológica (30), mas o consenso de quais dosagens devem ser utilizadas e qual o papel em infecções no trato respiratório, ainda carece de maiores evidências.

Aglipay et al. (31), compararam, em artigo de revisão, doses altas de vitamina D em relação às doses preconizadas para suplementação, e os efeitos em reduzir a incidência de infecções no trato respiratório em crianças, nos meses de inverno. Os achados deste trabalho demonstraram que, tanto participantes utilizando doses diárias de 400 UI tanto aqueles tomando doses de 2.000 UI não tiveram benefício alcançado na redução da incidência das infecções.

Já um estudo clínico fase 2 publicado por Lee et al. (32), comparou o impacto de duas dosagens de vitamina D $100.000 \mathrm{UI} / \mathrm{mês}$ ou $12.000 \mathrm{UI} / \mathrm{mês}$ (equivalentes a $3.333 \mathrm{UI} / \mathrm{d}$ e 400 $\mathrm{UI} / \mathrm{d}$ ) na prevenção de complicações relacionadas à infecções respiratórias em crianças com anemia falciforme. Independentemente das dosagens, os resultados demostraram impacto positivo nos participantes, reduzindo as complicações em até $50 \%$ dos casos.

Martineau et al. (33), em revisão sistemática publicada em 2017, avaliou a relação de suplementação de vitamina $\mathrm{D}$ e prevenção de infecções agudas no trato respiratório. Foram analisados dados de vinte e cinco estudos, com mais de 11.000 pacientes, de todas as faixas etárias. Os resultados dessa meta análise indicam que a suplementação de vitamina $\mathrm{D}$ pode ser uma alternativa segura para prevenção de infecções no trato respiratório. Entretanto, somente a concentração de 25 - hidroxivitamina D $(25(\mathrm{OH})$ vit D), foi levada em consideração, e não as dosagens diárias do suplemento. Ainda são encontrados dados positivos sobre os efeitos da suplementação de vitamina $\mathrm{D}$ e infecções virais $(34,38)$.

Dentre as vitaminas do complexo B, a vitamina B12 e o ácido fólico (B9), são as que possuem maiores níveis de investigação em relação ao sistema imune e infecções no geral. Estes compostos têm função de extrema importância na síntese de DNA e ácidos nucleicos, bem como no metabolismo de aminoácidos, proteínas, células vermelhas e formação do sistema nervoso central. No entanto, para infecções virais ou do trato respiratório, a literatura é muito antiga e poucos são os artigos sobre o assunto.

Taneja et al. (39), avaliaram o impacto do uso de folato e vitamina B12 no manejo de infecções do trato respiratório e diarreia em crianças na Índia. As dosagens utilizadas para cada vitamina foram duas vezes maiores do que as IDRs $(0,4 \mathrm{a} 0,9 \mu \mathrm{g} / \mathrm{dia})$, por um período de 18 meses, em 1.000 crianças de 6 a 30 meses. Os achados deste ensaio clínico não demonstraram vantagem em utilizar tais suplementos em relação a nenhum dos tipos de infecção analisadas.

Dentre os minerais, podemos destacar o zinco, que é essencial em diversos processos biológicos, principalmente para o adequado funcionamento do sistema imunológico, pois há uma relação direta com as células do sistema imune. Este mineral está associado à redução da mortalidade por pneumonia, conforme descrito em revisão Cochrane publicada por Lassi et al. (40) e no artigo publicado por Yakoob et al. (41). Ambos os artigos descrevem os efeitos positivos na redução da mortalidade ocasionada por pneumonia, em crianças. Porém, os dados apresentados nos artigos, estão relacionados à 
suplementação de zinco em pacientes de regiões menos favorecidas economicamente, o que poderia estar associado a um viés gerado pela subnutrição e carência de micronutrientes na composição da dieta das crianças.

Uma publicação de 2014 (42), relata o efeito positivo da suplementação de zinco em crianças indianas, como preventivo de infecções respiratórias. Os sujeitos da pesquisa possuíam quadros de imunossupressão, ocasionada pelo uso de corticosteroides, e a suplementação de zinco foi estimada em $20 \mathrm{mg} / \mathrm{dia}$, valor acima do recomendado pela IN n²8/18 (4 mg/d para crianças de 1 a 3 anos). Estes resultados podem carregar o viés de efeito positivo, provavelmente devido à carência do micronutriente e suplementação em doses acima das IDRs.

Saigai e Hanekom (43), concluíram que doses elevadas de zinco (75 mg/d), poderiam reduzir a duração dos sintomas de infecções respiratórias, mas não melhoram o quadro geral, diante de análise de alguns ensaios clínicos. Os autores também relatam que nos ensaios analisados, a deficiência de zinco não é levada em consideração, além de questionarem o tamanho da amostra dos artigos, formulação de zinco diferentes, terapias coadjuvantes e o tipo de patógeno da infecção.

Em relação ao selênio, este composto possui ação antioxidante, o que auxilia diretamente no fortalecimento e na proteção do sistema imunológico. Steinbrenner et al. (44), avaliaram o impacto dos efeitos de selênio em infecções virais e bacterianas. Os resultados demonstraram que selênio, isolado ou em combinação com outros micronutrientes (zinco), pode ser um adjuvante na prevenção e no avanço de determinadas patologias, sendo o mesmo considerado um nutriente essencial na dieta para manutenção de uma adequada resposta imunológica.

\section{5. Ômega 3}

Devido a seu potencial anti-inflamatório, os ácidos graxos ômega 3 poderiam ser opções interessantes no combate ao avanço de infecções do trato respiratório, uma vez que os mesmos tem potencial de inibir a formação de citocinas pró-inflamatórias, como cisteinilleucotrienos, reduzindo os impactos de doenças como asma e pneumonia, além de também participarem ativamente na resposta imunológica (45).

Além da expressão de citocinas inflamatórias, os ácidos graxos poli-insaturados, principalmente os ácidos eicosapentaenóico (EPA) e docosahexaenóico (DHA), exercem função importante na sinalização de células responsáveis pela resposta imunológica, como macrófagos, neutrófilos, células $\mathrm{T}$, células $\mathrm{B}$, células dendríticas, mastócitos, células natural killers (NK), basófilos e eosinófilos $(46,47)$.

Neste aspecto, os ácidos graxos ômega 3 são essenciais como nutrientes, mas o impacto positivo na resposta às infecções virais e bacterianas no trato respiratório e as dosagens diárias ainda precisam ser pesquisados de maneira mais criteriosa.

Husson et al. (48), analisaram os efeitos de ácidos graxos ômega 3 como moduladores da resposta imunológica em infecções virais e bacterianas. De acordo com os autores, no caso de Mycobacterium tuberculosis, Salmonella, Influenza e Herpes simplex, os dados são controversos, ocorrendo até maior incidência de eventos danosos em alguns casos. Esta mesma controvérsia de resultados em infecções virais, já havia sido descrita em artigo publicado por Anderson e Fritsche em 2002 (49). Seriam, então, necessários mais estudos clínicos controlados para que se possa obter melhores respostas sobre sua utilização em humanos.

A ação dos ácidos graxos ômega 3 no processo inflamatório relacionado à obesidade, já é bem descrita na literatura, devido ao seu potencial efeito na expressão e regulação de fatores de transcrição de genes, reduzindo a produção de citocinas como TNF- $\alpha$, IL-6, 
proteína reativa $\mathrm{C}(\mathrm{CRP})$ e aumentando lipoxinas, resolvinas e protectinas (50). Uma vez que o excesso de tecido adiposo e a alta ingestão de lipídeos tende a aumentar a produção destas citocinas durante a obesidade e, conforme já descrito, no avanço da COVID-19 são observados eventos inflamatórios importantes relacionados a uma "tempestade de citocinas", a utilização destes compostos em pacientes obesos acometidos da COVID-19 poderia reduzir a produção destes compostos, trazendo vantagens em relação aos eventos inflamatórios que podem agravar os sintomas da doença. Os possíveis efeitos positivos dos ácidos graxos ômega 3 necessitam ser investigados de maneira mais criteriosa, para que existam dados mais precisos sobre a resposta a estes compostos e evolução da doença nos casos de pacientes obesos (51).

\section{Proteína isolada do soro do leite (whey protein)}

Um suplemento que, recentemente, tem recebido grande destaque em estudos em diversas aplicações, é a proteína isolada do soro do leite (whey protein). Este composto, muito utilizado por atletas, ganhou espaço em diversas situações clínicas, devido ao seu alto valor biológico e seu potencial em regular diversas funções orgânicas. O produto já é utilizado como suplementação em pacientes com imunossupressão, idosos, crianças e em outras situações onde há aporte calórico e proteico inadequado, situações relacionadas a piora do estado nutricional e consequentemente da resposta imunológica.

Bun et al. (52), em artigo publicado em 2015, relataram as possíveis atividades antivirais de diferentes proteínas isoladas do soro do leite. Nesta revisão, os autores descrevem que as proteínas do soro do leite, teriam atividades contra diferentes tipos de vírus (HIV, rotavírus, $\mathrm{H} 1 \mathrm{~N} 1$, influenza, hantavírus, hepatite $\mathrm{C}$ ) e esta atividade seria de prevenção de infecções ocasionadas por estes patógenos. Os dados, apesar de serem, em sua maioria, em ensaios pré-clínicos, podem ser animadores e direcionar a possíveis ensaios clínicos de maior magnitude.

No caso de infecções do trato respiratório, Lothian et al. (53), avaliaram o impacto do uso de whey na resposta imunológica de pacientes com asma atópica. Os resultados foram pouco satisfatórios, utilizando um suplemento específico de whey protein, em doses relativamente baixas, por curto período de tempo. No entanto, há uma importante relação do uso de whey protein e seus efeitos sacietogênicos e insulinogênicos. Diante do fato de que doenças crônicas como obesidade e diabetes tendem a serem componentes ligados a fatores de risco, levando a agravos do curso da COVID-19, os efeitos de whey protein em pacientes obesos e com resistência à insulina deveriam ser investigados, sendo este suplemento uma possível estratégia nutricional para estes casos.

\section{Conclusão}

O presente trabalho teve como objetivo revisar, de forma narrativa, o papel dos suplementos alimentares na imunidade e sua possível utilização como ferramentas na prevenção e na evolução dos eventos ocasionados pela COVID-19. Os dados aqui apresentados sugerem que, o estado nutricional é fator determinante para uma boa resposta imunológica, e isso é alcançado no equilíbrio da disponibilidade de micro e macronutrientes. Em doses recomendadas pela legislação vigente, a maioria dos compostos apresenta impacto discreto quando analisados de forma isolada. Em alguns casos específicos, como o da vitamina D e vitamina B12, os artigos avaliados utilizaram dosagens maiores do que aquelas determinadas pela IN nº 28/2018 e IDRs, e os mesmos não promoveram efeitos positivos em relação à infecções respiratórias e virais, de um modo geral. Portanto, os suplementos alimentares são parte de uma estratégia nutricional, 
sendo estes direcionados àqueles que não conseguem, através da dieta, obter as quantidades mínimas de nutrientes necessários para a homeostasia metabólica e estes, juntamente a diversos outros fatores individuais, podem garantir o funcionamento normal do sistema imunológico. Como as infecções por coronavírus são recentes e há pouca informação disponível no meio científico, utilizar estes compostos como prevenção ao coronavírus ou mesmo para evitar os danos do agravamento da doença, carece de evidências robustas.

\section{Referências}

1. Organização Mundial da Saúde (OMS/WHO). Alerta mundial - pandemia COVID-19. Disponível em: https://www.who.int/dg/speeches/detail/who-director-general-s-opening-remarks-at-the-mediabriefing-on-covid-19 - 11-march-2020

2. Centers for Disease Control and Prevention: Severe Outcomes Among Patients with Coronavirus Disease 2019 (COVID-19) - United States, February 12-March 16, 2020. MMWR Morb Mortal Wkly Rep 69:343-346, 2020.

3. Singhal T. A Review of Coronavirus Disease-2019 (COVID-19). The Indian Journal of Pediatrics 2020; 87(4): 281-286.

4. Cao X. COVID-19: immunopathology and its implications for therapy. Nature Review Immunology 2020; 20: 269-270.

5. Dietz W, Santos-Burgoa C. Obesity and its Implications for COVID-19 Mortality. Obesity 2020; 28(6): 1005.

6. Lighter J, Phillips M, Hochman S, Sterling S, Johnson D, Francois F, et al. Obesity in patients younger than 60 years is a risk factor for Covid-19 hospital admission. Clin Infect Dis 2020; Apr 9: ciaa415.

7. Simonnet A, Chetboun M, Poissy J, Raverdy V, Noulette J, Duhamel A, et al. High prevalence of obesity in severe acute respiratory syndrome coronavirus-2 (SARS-CoV-2) requiring invasive mechanical ventilation. Obesity 2020; Apr 9.

8. Chandra RK, Sarchielli P. Nutritional Status and Immune Responses. Clinics in Laboratory Medicine 1993; 13(2): 455-461.

9. Helieh S. Nutrients, Infectious and Inflammatory Diseases. Nutrients 2017; 9: 1085.

10. ANVISA. Agência Nacional de Vigilância Sanitária. Resolução RDC nº 243 de 26 de julho de 2018. Dispõe sobre os requisitos sanitários dos suplementos alimentares.

11. ANVISA. Agência Nacional de Vigilância Sanitária. Instrução Normativa 28 de 26 de julho de 2018. Estabelece as listas de constituintes, de limites de uso, de alegações e de rotulagem complementar dos suplementos alimentares.

12. Felsensteina S, Herbertb JA, McNamarab PS, Hedrichb CM. COVID-19: Immunology and treatment options. Clinical Immunology 2020; 215: 108448.

13. Prompetchara E, Ketloy C, Palaga T. Immune responses in COVID-19 and potential vaccines: Lessons learned from SARS and MERS epidemic. Asian Pac J Allergy Immunol 2020; 38: 1-9

14. França TGD, Ishikawa LLW, Zorzella-Pezavento SFG, Chiuso-Minicucci F, da Cunha MLRS, Sartori A. Impact of malnutrition on immunity and infection. J Venom Anim Toxins incl Trop Dis 2009; 15(3): 375 .

15. Alwarawrah Y, Kiernan K, MacIver NJ. Changes in Nutritional Status Impact Immune Cell Metabolism and Function. Front Immunol 2018; 9:1055.

16. Kalligeros M, Shehadeh F, Mylona EK, Benitez G, CG, Beckwith, Chan PA. Association of Obesity with Disease Severity among Patients with COVID-19. Obesity (Silver Spring) 2020.

17. Simonnet A, Chetboun M, Poissy J, Raverdy V. Noulette J, Duhamel A. High Prevalence of Obesity in Severe Acute Respiratory Syndrome coronavirus-2 (SARS-CoV-2) Requiring Invasive Mechanical Ventilation. Obesity (Silver Spring). 2020.

18. Caussy C, Wallet F, Laville M, Disse E. Obesity is associated with severe forms of COVID-19. Obesity (Silver Spring) 2020. 
19. Berthon BS, Wood LG. Nutrition and Respiratory Health - Feature Review. Nutrients 2015; 7: 16181643.

20. Sayarlioglu H, Erkoc R, Demir C, Dogan E, Sayarlioglu M, Oner AF, Dilek I. Nutritional Status and Immune Functions in Maintenance Hemodialysis Patients. Mediators Inflamm 2006; 2006(1): 20264.

21. Aslam MF, Majeed S, Aslam S, Irfan JA. Vitamins: Key Role Players in Boosting Up Immune Response-A Mini Review. Vitam Miner 2017; 6:1.

22. Zhang L, Liu Y. Potential interventions for novel coronavirus in China: A systematic review. J Med Virol 2020; 92: 479-490.

23. Khaerunnisa S, Kurniawan H, Awaluddin R, Suhartati S, Soetjipto S. Potential Inhibitor of COVID-19 Main Protease (Mpro) from Several Medicinal Plant Compounds by Molecular Docking Study. Preprints 2020; 255: 2020030226.

24. Zhang D, Wub K, Zhang X, Deng S, Peng B. In silico screening of Chinese herbal medicines with the potential to directly inhibit 2019 novel coronavirus. J Integr Med 2020; 18(2): 152-158.

25. Huang Z, Liu Y, Qi G, Brand D, Zheng SG. Role of Vitamin A in the Immune System. J Clin Med 2018; 7: 258.

26. Chen H, Zhu Q, Yuan W, Wang J, WuT. Vitamin A for preventing acute lower respiratory tract infections in children up to seven years of age. Cochrane Database of Systematic Reviews 2008; 1 : CD006090.

27. Hemilä H. Vitamin C and Infections. Nutrients 2017; 9(4): 339.

28. Hemilä H, Louhiala P. Vitamin C for preventing and treating pneumonia (Cochrane Review). In: The Cochrane Library. 2008; 4.

29. Hemilä H, Chalker E. Vitamin C for preventing and treating the common cold. Cochrane Database of Systematic Reviews. 2013; 1.

30. Greiller CL, Martineau AR. Modulation of the Immune Response to Respiratory Viruses by Vitamin D. Nutrients 2015; 7: 4240-4270.

31. Aglipay M, Birken CS, Parkin PC, Loeb MB, Thorpe K, Math M, et al. Effect of High-Dose vs Standard-Dose Wintertime Vitamin D Supplementation on Viral Upper Respiratory Tract Infections in Young Healthy Children. JAMA 2017; 318(3): 245-254

32. Lee MT, Kattan M, Fennoy L, Arpadi SM, Miller RS, Cremers S, et al. Randomized phase 2 trial of monthly vitamin D to prevent respiratory complications in children with sickle cell disease. Blood Advances 2018; 2(9):969-978.

33. Martineau AR, Jolliffe DA, Hooper RL, Greenberg L, Aloia JF, Bergman P, et al. Vitamin D supplementation to prevent acute respiratory tract infections: systematic review and meta-analysis of individual participant data. BMJ. 2017; 356: i6583.

34. Larkin A, Lassetter J. Vitamin D Deficiency and Acute Lower Respiratory Infections in Children Younger Than 5 Years: Identification and Treatment. Journal of Pediatric Health Care 2014; 28(6): 572-82.

35. Beard JA, Beardena A, Strikera R. Vitamin D and the anti-viral state. Clin Virol 2011; 50(3): 194-200.

36. Borella E, Nesher G, Israeli E, Shoenfeld Y. Vitamin D: a new anti-infective agent? Ann. NY Acad Sci 2014; 1317: 76-83.

37. Yamshchikov AV, Desai NS, Blumberg HM, Ziegler TR, Tangpricha V. Vitamin D for treatment and prevention of infectious diseases: a systematic review of randomized controlled trials. Endocr Pract 2009; 15(5): 438-49.

38. Teymoori-Rad M, Shokri F, Salimi V, Marashi SM. The Interplay Between Vitamin D and Viral Infections. Rev Med Virol 2019; 29(2):e2032.

39. Taneja S, Strand TA, Kumar T, Mahesh M, Mohan S, Manger MS, Refsum H, Yajnik CS, Bhandari N. Folic acid and vitamin B-12 supplementation and common infections in 6230-mo-old children in India: a randomized placebo-controlled trial. Am J Clin Nutr 2013; 98: 731-7.

40. Lassi ZS, Moin A, Bhutta ZA. Zinc supplementation for the prevention of pneumonia in children aged 2 months to 59 months. Cochrane Database of Systematic Reviews 2016; 12(12):CD005978.

41. Yakoob MY, Theodoratou E, Jabeen A, Imdad A, Eisele TP, Ferguson J, et al. Preventive zinc supplementation in developing countries: impact on mortality and morbidity due to diarrhea, 
pneumonia and malaria. BMC Public Health 2011; 11 Suppl 3(Suppl 3):S23.

42. Malik A, Taneja DK, Devasenapathy N, Rajeshwari K. Zinc supplementation for prevention of acute respiratory infections in infants: a randomized controlled trial. Indian Pediatr 2014; 51(10): 780-4

43. Saigal P, Hanekom D. Does zinc improve symptoms of viral upper respiratory tract infection? Evidence-Based Practice 2020; 23(1): 37-39.

44. Steinbrenner H, Al-Quraishy S, Dkhil MA, Wunderlich F, Sies H. Dietary Selenium in Adjuvant Therapy of Viral and Bacterial Infections. Adv Nutr 2015; 6: 73-82.

45. Gutiérrez S, Svahn SL, Johansson ME. Effects of Omega-3 Fatty Acids on Immune Cells. Int J Mol Sci 2019; 20(20): 5028.

46. Ergas D, Eilat E, Mendlovic S, Sthoeger ZM. n-3 Fatty Acids and the Immune System in Autoimmunity. IMAJ 2002; 4: 34-38.

47. Fenton JI, Hord NG, Ghosh S, Gurzell EA. Long chain omega-3 fatty acid immunomodulation and the potential for adverse health outcomes. Prostaglandins Leukot Essent Fatty Acids 2013; 89(6): 379-390.

48. Husson M-O, Ley D, Portal C, Gottrand M, Hueso T, Desseyn J-L, Gottrand F. Modulation of host defence against bacterial and viral infections by omega-3 polyunsaturated fatty acids. Journal of Infection 2016; 73(6):523-535.

49. Anderson M, Fritsche KL. (n-3) Fatty Acids and Infectious Disease Resistance. The Journal of Nutrition. 2002; 132(12): 3566-3576.

50. Browning LM. n-3 Polyunsaturated fatty acids, inflammation and obesity-related disease. Proceedings of the Nutrition Society. 2003; 62, 447-453.

51. Rocha D, Lancha AH, Campos-Ferraz PL. Inflammatory Process in Obesity and the Effects of Omega3 Supplementation and Aerobic Exercise as Adjuvant Treatment. SM J Nutr Metab 2015; 1(1): 1004.

52. Bun NG, Cheung RCF, Wong JH, Wang Y, Ming DT, Wan DCC. Antiviral activities of whey proteins. Appl Microbiol Biotechnol 2015; 99: 6997-7008.

53. Lothian JB, Grey V, Lands LC. Effect of whey protein to modulate immune response in children with atopic asthma. International Journal of Food Sciences and Nutrition 2006; 57(3-4): 204-211. 